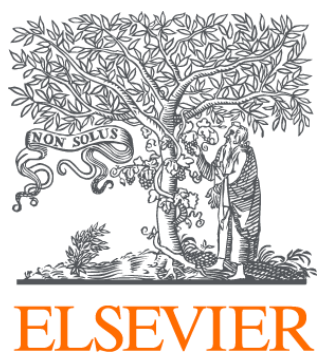

Since January 2020 Elsevier has created a COVID-19 resource centre with free information in English and Mandarin on the novel coronavirus COVID-

19. The COVID-19 resource centre is hosted on Elsevier Connect, the company's public news and information website.

Elsevier hereby grants permission to make all its COVID-19-related research that is available on the COVID-19 resource centre - including this research content - immediately available in PubMed Central and other publicly funded repositories, such as the WHO COVID database with rights for unrestricted research re-use and analyses in any form or by any means with acknowledgement of the original source. These permissions are granted for free by Elsevier for as long as the COVID-19 resource centre remains active. 
passed solutions to which additions had been made in 3 instancies (saline, potassium chloride, doxycycline).

The follow-up questionnaire evinced the following answers: Is it difficult to maintain sterility? $11 \%$ yes, Has leakage occurred? $48 \%$ yes, Slower-than-normal infusion? $89 \%$ yes, Did you feel it safer to use the filter? $7 \%$ yes,

What was your general impression of the usability of the filter?

very good $0 \%$, good $22 \%$, not very good $63 \%$, poor $11 \%$.

These replies and the many comments on the forms suggest that the nurses' low rating was due to the following factors:

(1) The tendency of the filter to become disconnected because the lack of a screw fitting. Nearly all infusion materials in Sweden have had luer-lock connections for at least five years.

(2) The tendency to slow the infusion down. More serious was the inability to speed up the infusion when needed (e.g., in a shocked patient).

(3) Incompatibility with all fluids for infusion.

(4) The filter was clumsy to use and difficult to secure and it drags on the cannula.

The mere existence of such a filter as this may be motivation enough for its use with certain high-risk groups (e.g., premature babies). Here common sense dictates that every precaution be taken against infusion-borne infection. With other groups of patients, the right policy seems less easy to determine. Even if the filters were equipped with a screw fitting to end the leakage difficulties, their unsuitability for all types of fluids, which is a considerable nuisance, would remain. When large volumes are given (peritoneal dialysis, burns) significant numbers of rubber, plastic, and glass particles are delivered to the patients. For these and other patients we do need better filtering capacity, and ideally one built in to the drip sets. The Ivex 2 does not seem to be the answer. A compromise between pore size and practicality is needed-i.e., a porosity that permits all kinds of fluids but holds back at least medium-to-large particles and maybe some bacteria as well.

Härnösands Sjukhus,

87101 Härnösand, Sweden

ROLF NiLZÉN

\section{LEAD AND RENAL DISEASE}

SIR, - You state (July 15, p. 140) "Lead-induced kidney disease has been recognised since 1909, when Turner related albuminuria to an outbreak of lead poisoning in Brisbane children". Priority for noting that lead causes kidney disease should probably be given to Wepser who is quoted by Baker ${ }^{1}$ as follows:

"Patients labouring under a bilious colic which is apt to end in palsy, give me great trouble ... Where white wines are drunk, this species of colic is very frequent . . viz., in Alsace . . there are likewise in those parts a greater number of gouty and nephritic patients ... I have suspected the cause to have been the taenia Sulphurata dulcis ... bismuth and lead."

Tanquerel des Planches ${ }^{2}$ who first described uric-acid stones in lead poisoning credited Wepser with identifying lead in wine as the cause of epidemic colic in 1671. In 1863 Lanceraux $^{3}$ reported that lead induces interstitial nephritis and further noted that albuminuria is by no means constant in lead nephropathy. Innumerable subsequent studies over the past century have made it clear that lead nephropathy is characterised by the absence of proteinuria. ${ }^{4}$ The editorial misstatement is particularly unfortunate because it tends to perpetuate the myth that proteinuria can be used to detect lead nephropathy.

Veterans Administration Hospital,

East Orange,

New Jersey 07019, U.S.A.

RICHARD P. WEEDEN

1. Baker, G. Med. Trans. Col. Phys. 1767, 339.

2. Tanquerel des Planches, L. Lead Disease: A Treatise. Boston, 1850.

3. Lancereaux, E. Archs Gen. Med.1881, 6, 641

4. Wedeen, R. P., Maesaka, J. K., Lyons, M. M., Vitale, L. F., Joselow, M. M. Am. Э. Med. 1975, 59, 630 .

\section{ROTAVIRUS INFECTIONS OF APES}

SIR,-We have seen typical rotavirus particles (figure) by electronmicroscopy of fæces from two young apes with diarrhœa.

On May 27, an 18-month-old chimpanzee in a zoo developed slight diarrhœe and anorexia. Fæces collected 2 days later contained small numbers of rotavirus particles. On May 28 a 15-month-old gorilla in the same cage began to vomit and later had diarrhoea. She was quite ill and did not return to normal health for 5 days. Fæces collected $12 \mathrm{~h}$ after onset contained large numbers of rotavirus particles.

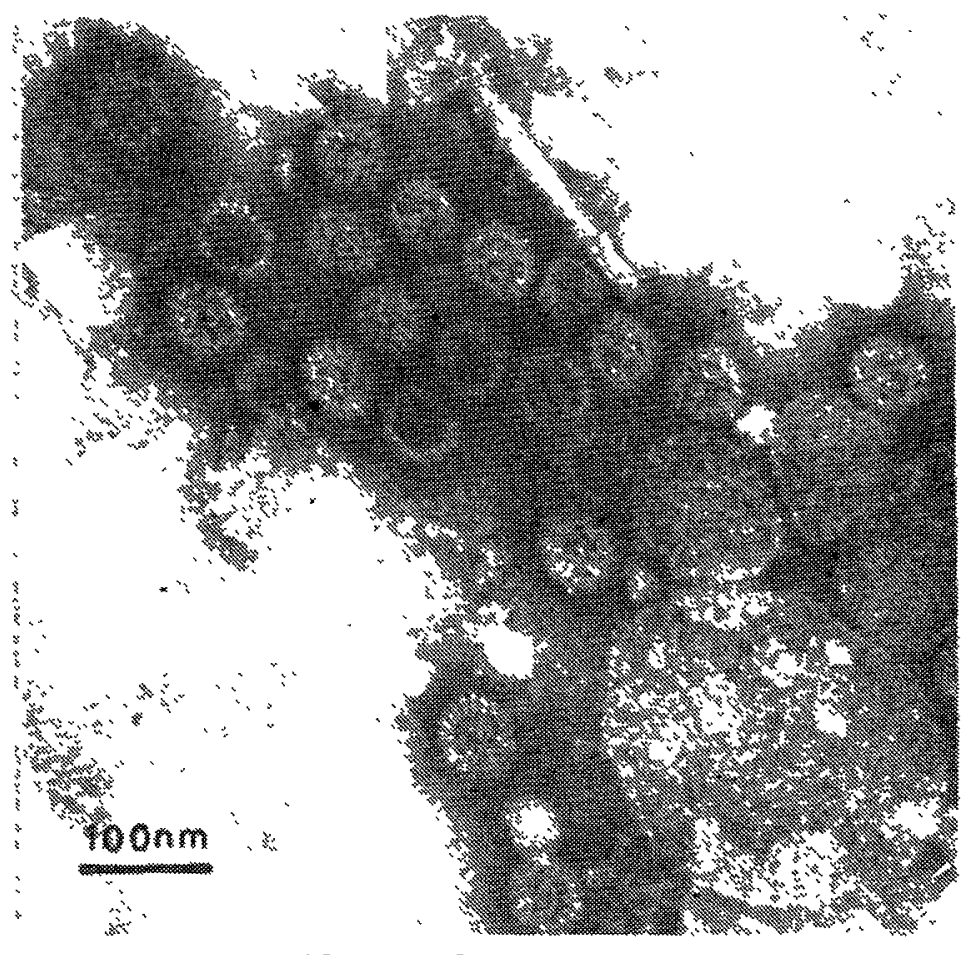

Rotaviruses isolated from ape fæces.

On inquiry it was found that between May 19 and 24 four other apes (two orang-utans and two gorillas-all adults or adolescents) in different cages in the same house had had mild diarrhœa with onset at 1-2 day intervals. A keeper aged 19, who had had diarrhœe on May 15-17 returned to work in the ape house on May 18. On May 13-14 he had stayed with a keeper from another zoo, who had had moderately severe gastroenteritis at the time.

The young chimpanzee was also excreting large numbers of coronavirus particles. Apes in this zoo and monkeys elsewhere are known to excrete coronaviruses frequently for long periods, so this was unlikely to be the cause of the outbreak. The rotavirus was a more likely candidate. This may have been a human or an ape strain. Since no new apes had been imported recently, the rotavirus may have been acquired from a member of the public, or from a keeper.

The human rotavirus has been shown to cause diarrhœa in colostrum-deprived newborn rhesus monkeys, but not in 8 day-old or juvenile rhesus monkeys. ${ }^{1}$ Holmes et al. ${ }^{2}$ were unable to produce diarrhœa in Macaca radiata with the human strain of rotavirus. The only simian rotavirus which has been described is SA-11, which was originally isolated from a symptom-free vervet monkey. ${ }^{3}$

C. R. AsHLEY

E. O. CAUL

S. K. R. ClaRke

Public Health Laboratory,

B. D. CORNER

Bristol BS2 8EL

S. DUNN

1. Wyatt, R. G., Sly, D. L., London, W. T., Palmer, A. E., Kalica, A. R., Van Kirk, D. H., Chanock, R. M., Kapıkıan, A. Z. Archs Virol: 1976, 50, 17.

2. Holmes, I. H., Mathan, M., Bhat, P., Albert, M. J., Swaminathan, S. P., Malya, P. P., Pereira, S. M., Baker, S. J. Lancet, 1974, ii, 658.

3. Malherbe, H. H., Harwin, R., Ulrich, M. S. Afr. med. f. 1963, 37, 407. 